\title{
The marine-derived fungal metabolite, terrein, inhibits cell proliferation and induces cell cycle arrest in human ovarian cancer cells
}

\author{
YI-FEI CHEN ${ }^{1}$, SHU-YING WANG ${ }^{1}$, HONG SHEN $^{1}$, XIAO-FEN YAO ${ }^{1}$, FENG-LI ZHANG ${ }^{2}$ and DONGMEI LAI \\ ${ }^{1}$ The International Peace Maternity and Child Health Hospital, School of Medicine, Shanghai Jiaotong University, \\ Shanghai 200030; ${ }^{2}$ Marine Biotechnology Laboratory, State Key Laboratory of Microbial Metabolism and \\ School of Life Sciences and Biotechnology, Shanghai Jiaotong University, Shanghai 200240, P.R. China
}

Received April 7, 2014; Accepted September 29, 2014

DOI: $10.3892 /$ ijmm.2014.1964

\begin{abstract}
The difficulties faced in the effective treatment of ovarian cancer are multifactorial, but are mainly associated with relapse and drug resistance. Cancer stem-like cells have been reported to be an important contributor to these hindering factors. In this study, we aimed to investigate the anticancer activities of a bioactive fungal metabolite, namely terrein, against the human epithelial ovarian cancer cell line, SKOV3, primary human ovarian cancer cells and ovarian cancer stem-like cells. Terrein was separated and purified from the fermentation metabolites of the marine sponge-derived fungus, Aspergillus terreus strain PF26. Its anticancer activities against ovarian cancer cells were investigated by cell proliferation assay, cell migration assay, cell apoptosis and cell cycle assays. The ovarian cancer stem-like cells were enriched and cultured in a serum-free in vitro suspension system. Terrein inhibited the proliferation of the ovarian cancer cells by inducing $\mathrm{G}_{2} / \mathrm{M}$ phase cell cycle arrest. The underlying mechanisms involved the suppression of the expression of LIN28, an important marker gene of stemness in ovarian cancer stem cells. Of note, our study also demonstrated the ability of terrein to inhibit the proliferation of ovarian cancer stem-like cells, in which the expression of LIN28 was also downregulated. Our findings reveal that terrein (produced by fermention) may prove
\end{abstract}

Correspondence to: Dr Dongmei Lai, The International Peace Maternity and Child Health Hospital, School of Medicine, Shanghai Jiaotong University, Hengshan Road 910, Shanghai 200030, P.R. China

E-mail: laidongmei@hotmail.com

Dr Feng-Li Zhang, Marine Biotechnology Laboratory, State Key Laboratory of Microbial Metabolism and School of Life Sciences and Biotechnology, Shanghai Jiaotong University, 800 Dongchuan Road, Shanghai 200240, P.R. China

E-mail: zhangfengli@sjtu.edu.cn

Key words: human epithelial ovarian cancer, cancer stem cell, terrein, LIN28 to be a promising drug candidate for the treatment of ovarian cancer by inhibiting the proliferation of cancer stem-like cells.

\section{Introduction}

Epithelial ovarian cancer is the most common and fatal gynecological malignancy, and is associated with a 5-year survival rate of approximately $30 \%$. The standard therapeutic strategy comprises optimal cytoreductive surgery followed by cisplatinbased systemic chemotherapy. Although the initial results of this debulking followed by chemotherapy are usually good, the majority patients relapse in $<5$ years due to chemoresistance (1-5). Several mechanisms have been reported to account for drug resistance (6), among which cancer stem cells have been widely studied in different tumor models over the past decade $(4,6,7)$.

According to this model, a pool of cancer stem cells, which are capable of both self-renewal and differentiation, is the initiating contributor towards tumor pathogenesis, drug resistance and recurrence (8-11). Cancer stem cells are highly resistant to chemotherapy due to their stem cell properties, mainly their quiescence and the expression of drug membrane transporters. Therefore, cancer stem cells can survive the therapy regimen and regenerate tumors, thus leading to relapse. The development of novel drug candidates and therapeutic strategies against ovarian cancer should therefore address the need to combat both differentiated and stem cell populations.

Previous studies have demonstrated the feasibility of isolating, enriching and propagating cancer stem-like cells (CSLCs), highly expressing stemness marker genes [such as aldehyde dehydrogenase $(A L D H 1), A L D H 2$, ATP-binding cassette, sub-family G (WHITE), member 2 (ABCG2), chemokine (C-X-C motif) receptor $4(C X C R 4)$, myeloid differentiation primary response $88(M y D 88)$ and lin-28 homolog A (C. elegans) (LIN28)] and being able to develop xenograft tumors with high efficiency from ovarian cancer cells (11-13). More importantly, CSLCs have been found not only in primary tumor samples, but also in immortalized cell lines and longterm culture cancer cells (14-17).

In our previous studies employing a serum-free suspension culturing system, we successfully enriched CSLCs 
from ovarian cancer cell lines in vitro (18-21). These CSLCs formed non-adherent spheroids and displayed remarkable stem cell properties, with higher drug resistance and tumorigenic efficiency than their differentiated counterparts. This system provides us with a valuable investigating system with which to screen novel drug candidates against human ovarian cancer cells (hOVCCs) and CSLCs.

In the present study, we aimed to investigate the anticancer effects of a bioactive fungal metabolite, namely terrein, against both hOVCCs and CSLCs. Terrein (4,5-dihydroxy-3-[(E)-1'propenyl]-2-cyclopenten-l-one, $\mathrm{C}_{8} \mathrm{H}_{10} \mathrm{O}_{3}$ ) was first isolated from Aspergillus terreus Thom in 1935 (22), and has since been tested in several applications across different fields, including the fields of medicine, cosmetology and agriculture (23-29). However, the biological function of terrein in targeting human diseases has not been extensively investigated. Studies have demonstrated the strong anti-proliferative effects of terrein on skin equivalents through the induction of $\mathrm{G}_{2} / \mathrm{M}$ cell cycle arrest $(27,30)$, suggesting its potential as a valuable candidate for treating hyper-proliferative skin diseases. However, the antitumor activity of terrein remains to be investigated.

In our previous studies, we successfully isolated the (+)-terrein from the fermentation broth of the marine sponge-derived fungus, Aspergillus terreus strain PF26, with high production efficiency and high quality $(31,32)$. In the present study, we aimed to investigate the anticancer effects of terrein isolated in this manner on a human epithelial ovarian cancer model.

\section{Materials and methods}

Terrein preparation and cell culture. Terrein was separated from the fermentation broth of Aspergillus terreus strain PF-26 (31,32), and subjected to identification and quantification by high-performance liquid chromatography (HPLC) as previously described (31). The human ovarian epithelial cancer cell line, SKOV3, was purchased from the Shanghai Cell Bank of the Chinese Academy of Sciences (Shanghai, China). Adherent SKOV3 cells were cultured in regular culture plates at $37^{\circ} \mathrm{C}$, in a humidified environment containing $5 \% \mathrm{CO}_{2}$ with the McCoy's 5A medium (Sigma-Aldrich, St. Louis, MO, USA), supplemented with $10 \%$ fetal bovine serum (FBS; HyClone, Logan, UT, USA), $100 \mathrm{units} / \mathrm{ml}$ penicillin and $100 \mu \mathrm{g} / \mathrm{ml}$ streptomycin.

Primary human epithelial ovarian tumor cells were isolated from the tumors of 3 patients classified as stage III, grade 2-3 serous adenocarcinoma according to the International Federation of Gynecology and Obstetrics (FIGO) classification. The study was approved by the Institutional Review Board at Shanghai Jiaotong University (Shanghai, China). The cells were cultured in the McCoy's 5A medium (Sigma-Aldrich), supplemented with $10 \%$ fetal bovine serum (FBS; HyClone), $100 \mathrm{units} / \mathrm{ml}$ penicillin and $100 \mu \mathrm{g} / \mathrm{ml}$ streptomycin. Cisplatin was purchased from Sigma-Aldrich, dissolved in DMSO and added to the culture medium where indicated.

Enrichment of CSLCs. Ovarian CSLCs were enriched as previously described (21). Upon reaching $80 \%$ confluence, the SKOV3 cells were dissociated by $0.25 \%$ Trypsin-EDTA (Life Technologies, Carlsbad, CA, USA) for $1-2 \mathrm{~min}$ at $37^{\circ} \mathrm{C}$. Single cells were suspended in DMEM/F12 medium supplemented with $10 \mathrm{ng} / \mathrm{ml}$ basic fibroblast growth factor (bFGF; Invitrogen,
Carlsbad, CA, USA) and 10\% knockout serum (Gibco, Grand Island, NY, USA) in low attachment plates. The medium was renewed every 2 days following centrifugation at $800 \mathrm{rpm}$ for $5 \mathrm{~min}$ to remove the dead cell debris. After 7 days, spheroidshaped CSLCs were selected for further treatment or analysis.

Cell viability assay. 3-(4,5-Dimethylthiazol-2-yl)-2,5-diphenyl tetrazolium bromide (MTT) assay was employed to measure cell viability. Approximately $1 \times 10^{4}$ cells were seeded per well in a 96-well plate and allowed to attach overnight. The culture medium was replaced with fresh medium containing terrein (or PBS as mock treatment). Following 48 or $72 \mathrm{~h}$ of treatment, cell viability was determined by MTT assay. The cells were incubated with $10 \mu \mathrm{l}$ MTT ( $5 \mathrm{mg} / \mathrm{ml}$; Sigma-Aldrich) added to the medium for $4 \mathrm{~h}$ at $37^{\circ} \mathrm{C}$. The medium was then removed and the converted dye was solubilized with $150 \mu$ l DMSO (dimethyl sulfoxide; Sigma-Aldrich). Absorbance at $490 \mathrm{~nm}$ was measured on a microplate reader (Bio-Rad, Hercules, CA, USA). Each assay was repeated in at least 6-wells and each experiment was independently repeated 3 times.

Transwell assay. The migratory ability of the cells was determined by Transwell assay as previously described (21). Briefly, the cells were seeded into the top chamber of $8.0 \mu \mathrm{m}$ Transwell invasion chambers (Corning Inc., Corning, NY, USA) in serum-free medium. Complete medium was added to the lower chambers. The cells were allowed to migrate for $24 \mathrm{~h}$ before being fixed in methanol and visualized by crystal violet staining. The cells which did not migrate to the lower chamber were removed by scraping. At least 3 random microscope fields of view were observed.

Cell cycle analysis. Cell cycle analysis was performed as previously described (21). The SKOV3 cells were seeded in 6-cm dishes at a density of $3 \times 10^{5}$ cells/dish and allowed to attach and proliferate for $24 \mathrm{~h}$. After being treated with $15 \mathrm{mg} / \mathrm{l}$ terrein for $24 \mathrm{~h}$, the cells were harvested by trypsin digestion, before being washed with PBS and fixed with 70\% cold-ethanol for $24 \mathrm{~h}$ at $-20^{\circ} \mathrm{C}$. The cells were treated with RNase A for $30 \mathrm{~min}$ at $37^{\circ} \mathrm{C}$, and then stained with propidium iodide (PI) for $30 \mathrm{~min}$ at $4^{\circ} \mathrm{C}$. The cells were analyzed using a Cytomics ${ }^{\mathrm{TM}}$ FC500 flow cytometer (Beckman Coulter, Brea, CA, USA). Data were analyzed using Beckman Coulter CXP software.

Analysis of cell apoptosis. Following incubation with or without $15 \mathrm{mg} / \mathrm{l}$ terrein for $48 \mathrm{~h}$, the SKOV3 cells were harvested and analyzed as previously described (33). Cell apoptosis assay was performed using the Annexin V-FITC Apoptosis Detection kit (Nanjing KeyGen Biotech Co., Ltd., Nanjing, China) according to the manufacturer's instructions. The cells were analyzed using a Cytomics FC500 flow cytometer (Beckman Coulter).

Western blot analysis. The cells were washed in cold PBS, and lysed in lysis buffer [50 mM Tris (pH 7.4), $150 \mathrm{mM} \mathrm{NaCl}$, $1 \%$ Triton X-100, $1 \%$ sodium deoxycholate, $0.1 \%$ SDS, $1 \mathrm{mM}$ phenylmethylsulfonyl fluoride, $20 \mu \mathrm{g} / \mathrm{ml}$ aprotinin and $25 \mu \mathrm{g} / \mathrm{ml}$ leupeptin] for $30 \mathrm{~min}$ on ice. Protein was quantified by a standard BCA assay (Pierce Biotechnology, Rockford, IL, USA). Total protein $(50 \mu \mathrm{g})$ was loaded, separated by SDS-PAGE gel, transferred onto PVDF membranes and incubated with 
specific antibodies overnight at $4^{\circ} \mathrm{C}$. The antibodies used in the present study were rabbit monoclonal antibodies against LIN28 (1:50,000; Epitomics, Burlingame, CA, USA), against Cdc2 (1:10,000; Epitomics), against cyclin B1 (1:5000; Epitomics) and rabbit polyclonal antibodies against GAPDH $(1: 2,000$; HangZhou HuaAn Biotechnology Co., Ltd, Hangzhou, China). This was followed by incubation with HRP (horseradish peroxidase)-conjugated anti-rabbit IgG secondary antibodies (1:1,000; Beyotime Institute of Biotechnology, Shanghai, China) for $1 \mathrm{~h}$ at room temperature. Immunoblot signals were visualized using SuperSignal West Pico Chemiluminescent Substrate (Pierce Biotechnology).

Quantitative PCR. RNA extraction and quantitative PCR were performed as previously described (33). The cells were harvested after being rinsed with PBS; RNA was extracted using TRIzol reagent (Life Technologies) according to the manufacturer's instructions. DNase I (Fermentas, Hanover, MD, USA) was used to exclude genomic DNA contamination. cDNA was synthesized with random primers by a ReverTra Aca- $\alpha$ kit (Toyobo Co., Ltd., Osaka,. Japan). The expression of $A L D H 1, A L D H 2, A B C G 2, C X C R 4$ and $M y D 88$ was evaluated by quantitative PCR. Quantitative PCR was performed with SYBR-Green real-time PCR Master Mix Plus (Toyobo) using Mastercycler ep realplex (Eppendorf, Hamburg, Germany). The primers used in the present study are listed in Table I.

\section{Results}

Anti-proliferative effects of terrein on human epithelial ovarian cancer cells. We extracted and purified terrein from the fermentation broth of the marine sponge-derived fungus, Aspergillus terreus strain PF26, with high production efficiency and high quality as previously described $(31,32)$. The structure of terrein is illustrated in Fig. 1A. To determine whether terrein exerts anticancer effects against human epithelial ovarian cancer, we first evaluated its anti-proliferative effects on a cisplatin-resistant human epithelial ovarian cancer cell line (SKOV3).

As shown in Fig. 1B, cisplatin, used as a clinical reference, displayed moderate anticancer activity against the SKOV3 cells. By contrast, treatment with terrein led to a more effective suppression of cell proliferation: following $48 \mathrm{~h}$ of incubation with $15 \mathrm{mg} / \mathrm{l}$ terrein, only 50 viable SKOV3 cells remained. This suggests that terrein effectively inhibits the proliferation of immortalized ovarian cancer cells.

To investigate the effects of terrein on cell migration, we performed a Transwell migration assay and compared the migration of the cells treated either with PBS (mock treatment) or incubated with terrein for $24 \mathrm{~h}$. After $24 \mathrm{~h}$, the number of cells that had migrated to the bottom of the wells was significantly reduced following treatment with terrein (Fig. 1C), indicating that terrein attenuated the migration of SKOV3 cells. These data indicate that terrein exerts anticancer effects on ovarian cancer cells (SKOV3).

Terrein induces $G_{2} / M$ phase cell cycle arrest. To better characterize the anticancer activity of terrein and investigate the mechanisms underlying its anti-proliferative effects, we examined its effects on apoptosis and the cell cycle. We used SKOV3 cells, which were harvested after $48 \mathrm{~h}$ of incubation with
Table I. Primers used for quantitative PCR.

\begin{tabular}{ll}
\hline Primer & \multicolumn{1}{c}{ Sequence $\left(5^{\prime} \rightarrow 3^{\prime}\right)$} \\
\hline 18 s rRNA-F & CGGCGACGACCCATTCGAAC \\
18 s rRNA-R & GAATCGAACCCTGATTCCCCGTC \\
LIN28-F & AGTGGCCTGGATAGGGAAGT \\
LIN28-R & CTTGGCTCCATGAATCTGGT \\
ALDH1-F & TGTTAGCTGATGCCGACTTG \\
$A L D H 1-\mathrm{R}$ & TTCTTAGCCCGCTCAACACT \\
$A L D H 2-\mathrm{F}$ & TTCAACCAGGGCCAGTGCTGCTGT \\
$A L D H 2-\mathrm{R}$ & CCCCTCTTGCTTCCCCGTGTTGAT \\
$A B C G 2-\mathrm{F}$ & TGAGCCTTTGGTTAAGACCG \\
$A B C G 2-\mathrm{R}$ & TGGTGTTTCCTTGTGACACTG \\
$C X C R 4-\mathrm{F}$ & GGTGGTCTATGTTGGCGTCT \\
$C X C R 4-\mathrm{R}$ & TGGAGTGTGACAGCTTGGAG \\
$M y D 88-\mathrm{F}$ & GCACATGGGCACATACAGAC \\
$M y D 88-\mathrm{R}$ & TAGCTGTTCCTGGGAGCTGT
\end{tabular}

F, forward, R, reverse.

$15 \mathrm{mg} / \mathrm{l}$ terrein. Flow cytometric analysis was performed using Annexin V-FITC to label the apoptotic cells and PI to stain the necrotic cells. As shown in Fig. 2A, terrein moderately induced cell apoptosis: the percentage of early apoptotic cells increased from 0.99 to $3.02 \%$ [indicated by Annexin V-FITC(+)/PI(-) labeling], and the late apoptotic percentage slightly increased from 2.19 to $3.71 \%$ [indicated by Annexin V-FITC(+)/PI(+) labeling].

We then analyzed the cell cycle distribution by staining the cells with PI. As illustrated in Fig. 2B, 24 h of treatment with $15 \mathrm{mg} / \mathrm{l}$ terrein led to a significant increase (from $\sim 18.14$ to $\sim 58.81 \%$ ) in the number of SKOV3 cells at the $\mathrm{G}_{2} / \mathrm{M}$ phase of the cell cycle. To better understand the ability of terrein to induce cell cycle arrest, we examined the expression of cyclin B1 and Cdc2, both of which play essential roles in the control of the cell cycle at the $\mathrm{G}_{2} / \mathrm{M}$ phase $(34,35)$. Protein detection by western blot analysis revealed a notable depletion in the levels of both cyclin B1 and Cdc2 (Fig. 2C), suggesting that terrein modified the expression of the cell cycle regulators and consequently induced cell cycle arrest.

Terrein suppresses the expression of LIN28 in ovarian cancer cells. The RNA-binding protein, LIN28, has been reported to bind to and promote the translation of certain mRNAs encoding cell cycle regulators, including cyclin B1 (36-40), and thereby coordinates the cell cycle at multiple checkpoints. More importantly, LIN28 has been shown to contribute towards the malignancy of ovarian cancer and is thus believed to be a potential target for ovarian cancer therapy $(41,42)$. It also should be noted that LIN28 is used to define stemness in several tissue lineages and, when highly expressed, is associated with the stemness properties of ovarian cancer stem cells (43-45).

To gain insight into the anticancer mechanisms of terrein, we investigated whether it affects the expression of LIN28 in SKOV3 cells. Firstly, we assessed LIN28 expression at the 
A

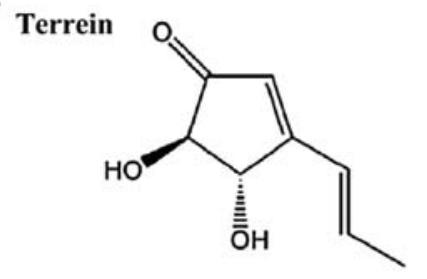

C

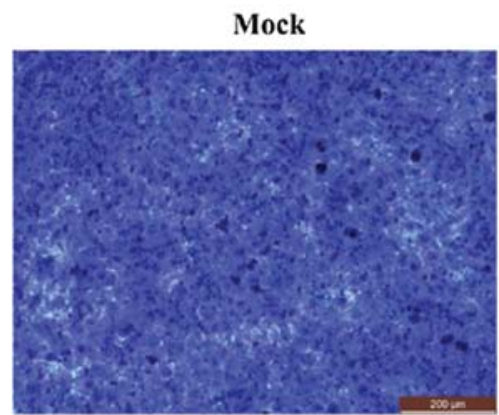

B
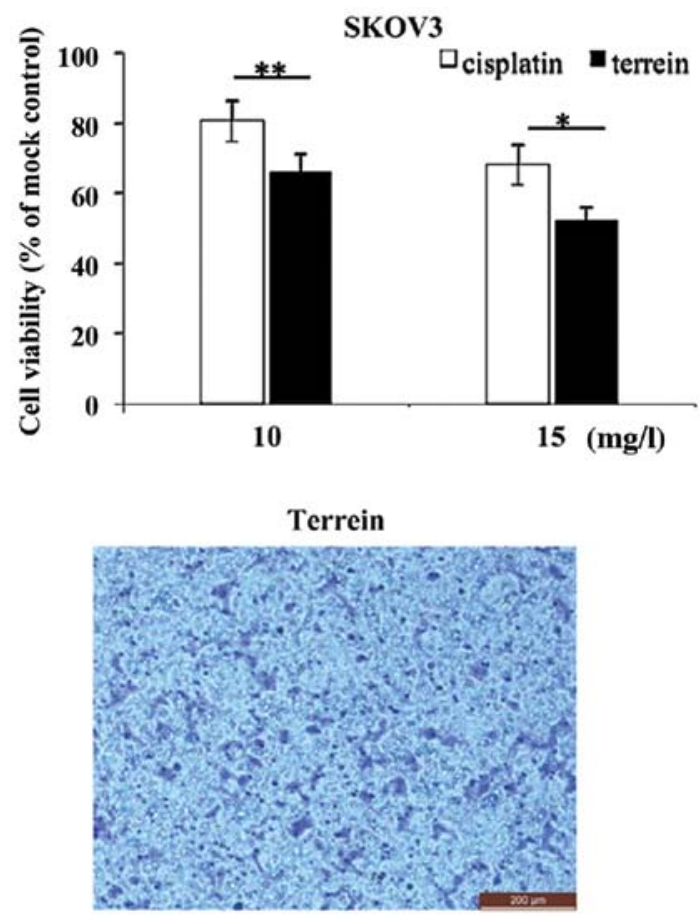

Figure 1. Terrein inhibits the proliferation and migration of human epithelial ovarian cancer cells (SKOV3). (A) Structure of terrein. (B) Cell viability was determined by MTT assay. Cells were incubated with 10 or $15 \mathrm{mg} / 1$ terrein or cisplatin for $48 \mathrm{~h}$ prior to analysis. An equal amount of PBS or DMSO was used as the mock treatment. Each experiment was performed in triplicate, and data are presented as the means \pm standard deviation $(\mathrm{SD})\left({ }^{* *} \mathrm{P}<0.01\right.$; $\left.{ }^{*} \mathrm{P}<0.05\right)$. (C) Migratory ability of SKOV3 cells was determined by Transwell assay. Cells were treated with PBS (mock) or terrein for $24 \mathrm{~h}$ prior to Transwell assay. Cells, which migrated through the membrane, were visualized by crystal violet staining. Images illustrate representative results. Scale bar, $200 \mu \mathrm{m}$.

A

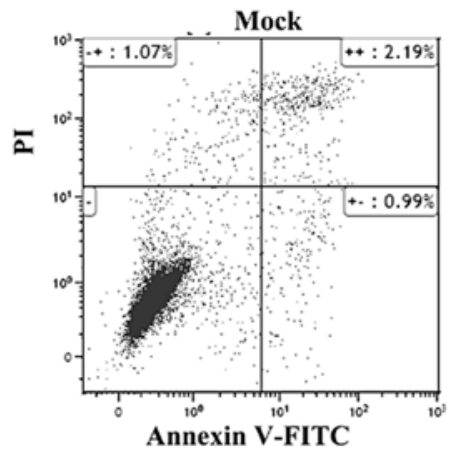

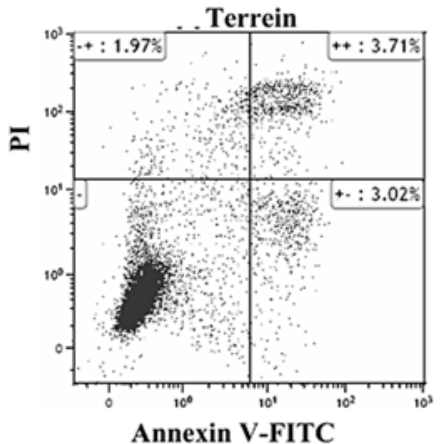

Terrein
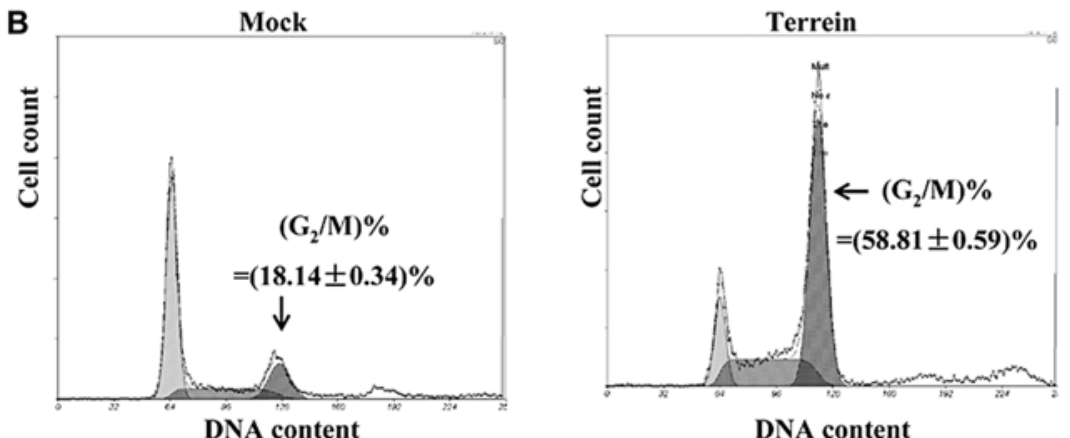

C

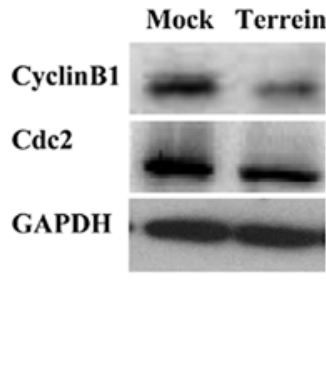

Figure 2. Effects of terrein on apoptosis and cell cycle in SKOV3 cells. (A) Apoptotic cells were detected by flow cytometric analysis. Annexin V-FITC(+)/PI(-) staining indicated the early apoptotic cells, while Annexin V-FITC $(+) / \mathrm{PI}(+)$ labeled the late apoptotic cells. Numbers indicate the percentage cells in each phase. 'Mock' represents the PBS-treated cells. Three independent experiments were performed, and similar results were obtained. Flow cytometry charts represent 1 of 3 independent experiments. (B) Propidium iodide (PI) was used to stain cellular DNA and flow cytometry was performed to analyze cell cycle contribution. 'Mock' represents the PBS-treated cells. Three independent assays were performed, and numbers indicate the means \pm SD percentage of cells at the $\mathrm{G}_{2} / \mathrm{M}$ stage. (C) Western blot analysis was performed to detect cyclin B1 and Cdc2 expression in SKOV3 cells. 'Mock' signifies cells treated with PBS, and 'Terrein' signifies cells treated with $15 \mathrm{mg} / 1$ terrein for $48 \mathrm{~h}$. GAPDH was applied as reference. 
A

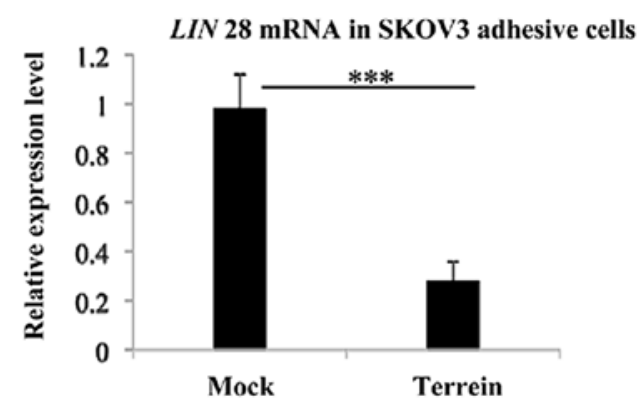

B

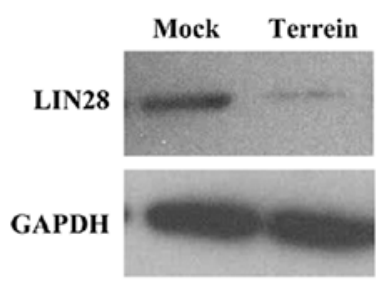

Figure 3. Terrein suppresses the expression of LIN28 in SKOV3 cells. (A) Quantitative PCR was performed to quantify the transcript levels of LIN28 in SKOV3 cells. 18s rRNA was employed as the internal standard and the relative transcript concentration was normalized to mock cells which were treated with PBS Results present the average of at least 3 independent experiments, and the error bars indicate the standard deviation $\left({ }^{* * * *} \mathrm{P}<0.001\right)$. (B) Western blot analysis was performed to detect LIN28 protein epxression in SKOV3 cells. 'Mock' signifies cells treated with PBS, and 'Terrein' signifies cells treated with $15 \mathrm{mg} / \mathrm{l}$ terrein for $48 \mathrm{~h}$. GAPDH was applied as reference.
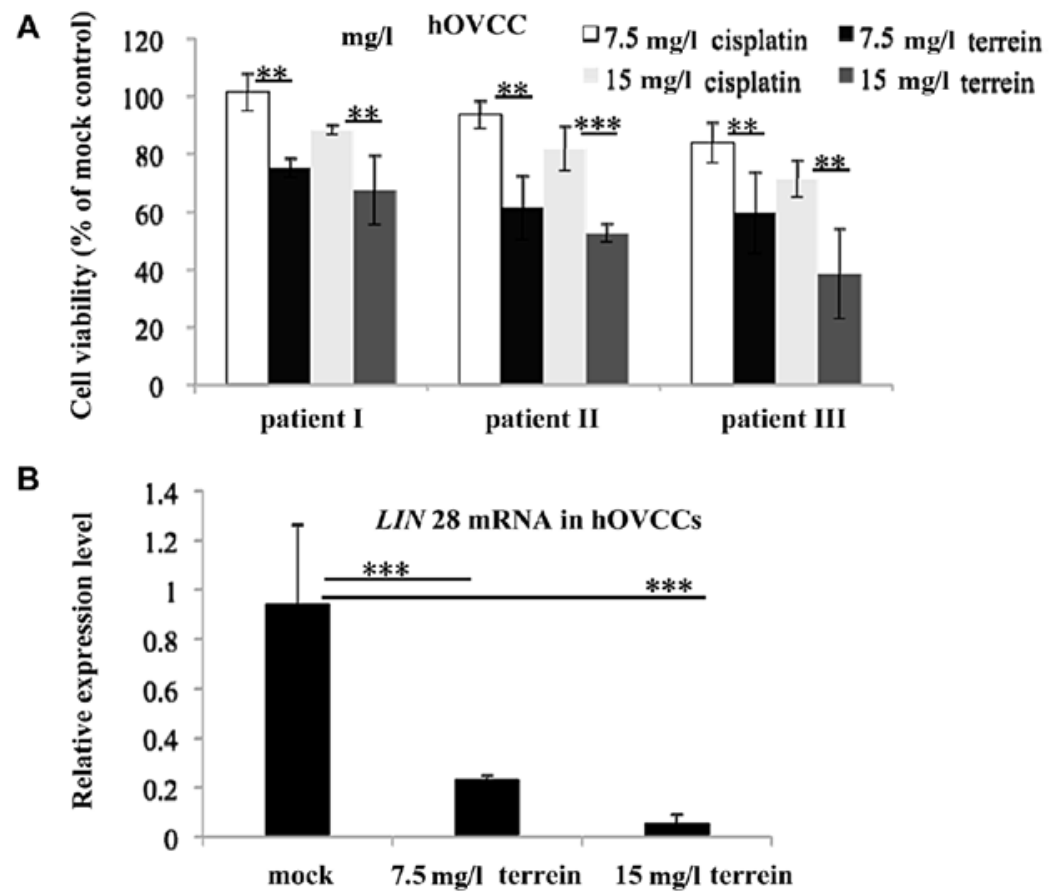

Figure 4. Anti-proliferative activity of terrein and its suppressive effects on LIN28 expression effect in primary human ovarian cancer cells (hOVCCs). (A) MTT assay was performed to detect the viability of hOVCCs. Cells were treated with 7.5 or $15 \mathrm{mg} / \mathrm{l}$ cisplatin or terrein for $48 \mathrm{~h}$. Equal amounts of DMSO or PBS were used as the mock control. Each experiment was performed in triplicate, and data shown are the means $\pm \mathrm{SD}\left({ }^{* * * *} \mathrm{P}<0.001\right.$; $\left.{ }^{* *} \mathrm{P}<0.01\right)$. (B) mRNA expression of LIN28 in hOVCCs was detected by quantitative PCR. 'Mock' signifies cells treated with PBS. 18s rRNA was applied as an internal standard control. Results represent the average of at least 3 independent experiments, and the error bars indicate the standard deviation $\left({ }^{* * * *} \mathrm{P}<0.001\right)$.

transcriptional level by quantitative PCR, and observed a clear decrease following incubation of the cells with terrein (Fig. 3A). Using western blot analysis, we then examined the suppressive effects of terrein on LIN28 at the translational level. As shown in Fig. 3B, the level of LIN28 protein was significantly depleted in the SKOV3 cells which had been incubated with terrein for $48 \mathrm{~h}$.

In order to further confirm the anti-proliferative effects of terrein on epithelial ovarian cancer cells, we examined the anticancer effects of terrein on primary hOVCCs isolated from the tumors of 3 patients, classified as stage III, grade 2-3 serous adenocarcinoma. MTT assay revealed that treatment with terrein led to an marked reduction in cell viability (Fig. 4A). Although the anti-proliferative effects were not uniform on the different samples, the efficiency of terrein was consistently higher than that of cisplatin. In accordance with the results obtained with the SKOV3 cells, terrein also downregulated the expression of LIN28 in the hOVCCs (Fig. 4B). These results indicate that terrein exerts anti-proliferative effects and suppresses the expression of LIN28 in both immortalized cells and primary hOVCCs.

Terrein effectively inhibits the survival of CSLCs. Since terrein downregulated the expression of LIN28 in the hOVCCs, we wished to determine whether it would have the same effects on ovarian cancer stem cells, in which LIN28 has been reported to be an essential regulator (38-45). 
A

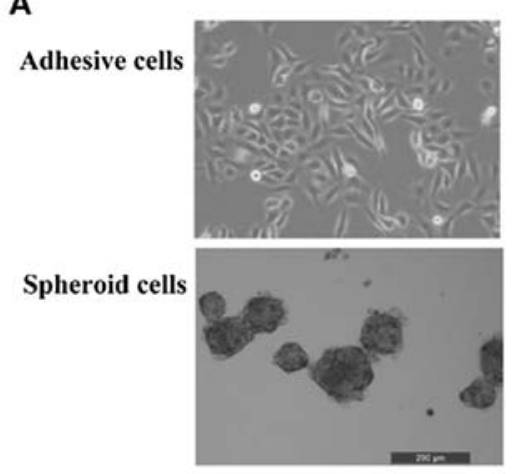

C

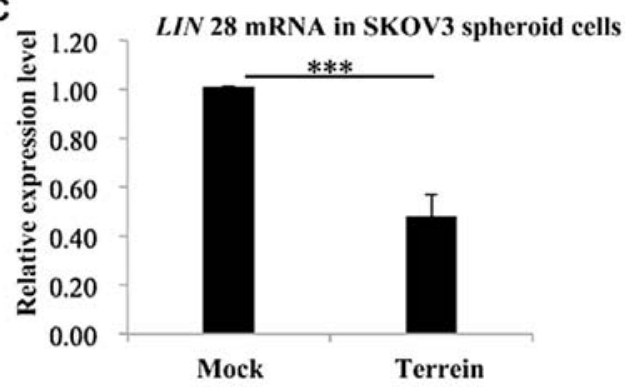

E

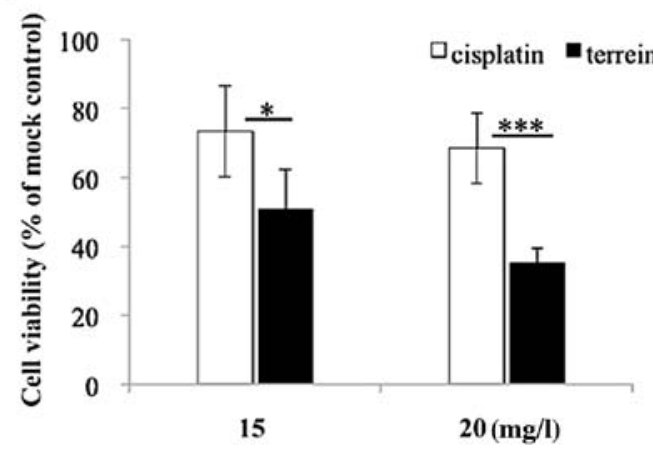

B

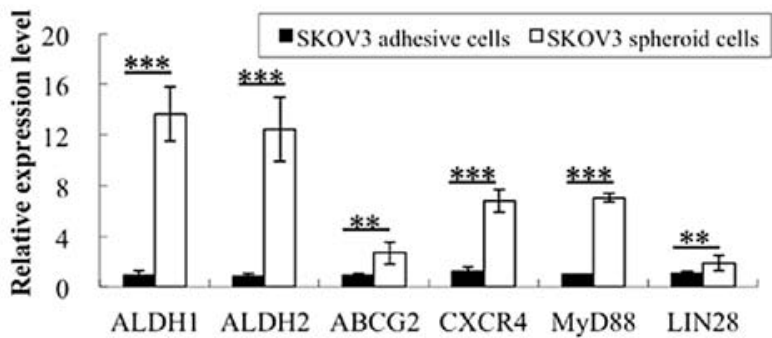

D

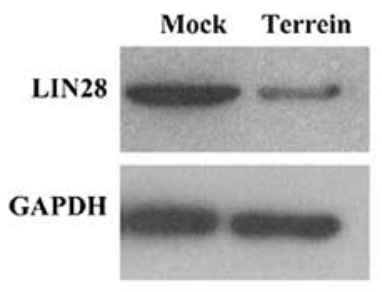

$\mathbf{F}$

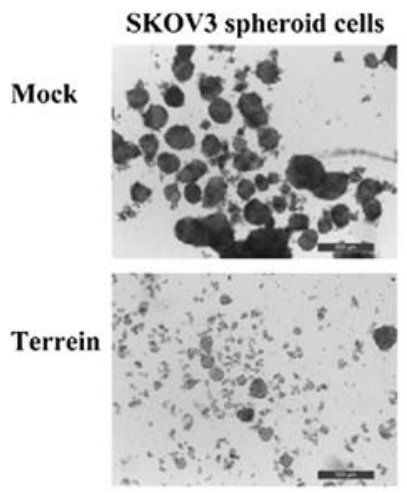

Figure 5. Terrein exerts anticancer effects against ovarian cancer stem-like cells. (A) Differentiated SKOV3 cells grew as adherent cells, while the cancer stem-like cells formed spheroids in serum-free suspension culture system. Scale bare, $200 \mu \mathrm{m}$. (B) Quantitative PCR was performed to determine the relative expression level of cancer stem cell marker genes. 18s rRNA was applied as internal standard control. Results present the average of at least 3 independent experiments, and the error bars indicate the standard deviation $\left({ }^{* * *} \mathrm{P}<0.001 ;{ }^{* * *} \mathrm{P}<0.01\right)$. (C) mRNA expression of $L I N 28$ in SKOV3 spheroid cells was detected by quantitative PCR. 'Mock' signifies cells treated with PBS. 18s rRNA was applied as an internal standard control. Results present the average of at least 3 independent experiments, and the error bars indicate the standard deviation ( $\left.{ }^{*}{ }^{* *} \mathrm{P}<0.001\right)$. (D) Western blot analysis was performed to detect LIN28 protein expression in SKOV3 spheroid cells. 'Mock' signifies cells treated with PBS and 'Terrein' signifies cells treated with 15 mg/l terrein for 48 h. GAPDH was applied as a reference. (E) MTT assay was performed to determine the remaining number of viable cells following treatment with terrein for 72 h; an equal amount of cisplatin was used. Each experiment was performed in triplicate, and error bars indicate the standard deviation $\left({ }^{* * *} \mathrm{P}<0.001\right.$; $\left.{ }^{*} \mathrm{P}<0.05\right)$. $(\mathrm{F}) \mathrm{Morphological} \mathrm{changes}$ of SKOV3 spheroid cells, which were incubated with terrein for $72 \mathrm{~h}$. 'Mock' signifies cells treated with PBS. Scale bar, $500 \mu \mathrm{m}$.

We have previously reported the feasibility of enriching and propagating human ovarian CSLCs by culturing SKOV3 spheroid cells under serum-free conditions (18-21). Employing this serum-free culture system, we examined the anticancer effects of terrein on CSLCs. As shown in Fig. 5A, the enriched CSLCs grew as spheroid-shaped cells and could be easily distinguished from the original differentiated SKOV3 adhesive cells. To further confirm the stem cell characteristics of the CSCLs, we assessed the expression levels of several cancer stem cell markers including, $A L D H 1, \underline{A L D H 2}, A B C G 2$, CXCR4, MyD88 and LIN28. Quantitative PCR revealed that the expression of these markers was noticeably increased in the spheroid-shaped cells (Fig. 5B), thus, validating their cancer stem cell-like properties.
As shown in Fig. 5B, the enriched CSLCs displayed higher expression levels of LIN28 compared to the original SKOV3 cells. Of note, treatment with terrein significantly reduced the expression of LIN28 in the CSLCs at both the transcriptional and translational levels (Fig. 5C and D). Encouraged by this result, we examined the anti-proliferative effects of terrein on the CSCLs (Fig. 5E). The result showeds that cisplatin exhibited only a moderate effect in spheroid cells; however, treatment with terrein significantly depleted the cell survival of the SKOV3derived CSLCs (Fig. 5E); incubation with $15 \mathrm{mg} / 1$ terrein for $72 \mathrm{~h}$ reduced cell viability by $\sim 50 \%$. Fig. $5 \mathrm{~F}$ shows the morphological changes of SKOV3 spheroid-shaped cells following treatment with terrein: the spheroids were dispersed into single cells; treatment for a longer duration led to cell death. 
Taken together, the results from our study demonstrate that terrein suppresses the expression of LIN28 and exerts antiproliferative effects against ovarian CSLCs.

\section{Discussion}

Over the past decade, there is increasing evidence supporting the cancer stem cell theory, and cancer stem cells have been successfully separated from both primary tumor samples and immortalized cell lines $(6,7,11)$. The separated cancer stem cells have been shown to survive in an in vitro serum-free culture system, forming spheroids and exhibiting stem-like properties $(11,12)$. This in vitro system provides a valuable model for the screening and determining the underlying mechanisms of action of drugs against human cancers, particularly those resistant to drugs.

Epithelial ovarian cancer is the most lethal gynecological malignancy, which easily develops drug resistance, thus causing relapse (1-5). The cancer stem cell theory has significant therapeutic implications and provides a mechanistic explanation for ovarian cancer carcinogenesis and development. Based on this theory, novel drugs targeting cancer stem cells are urgently required; however, little is known at present (46).

In this study, we demonstrate that one small compound, namely terrein, effectively exerts anticancer effects in both differentiated and stem-like ovarian cancer cells. Terrein is a fungal metabolite which has already been shown to have valuable bioactivity in the fields of medicine, cosmetology and agriculture without any cytotoxic effects (22-30). In the present study, we separated terrein from the fermentation broth of sponge-derived fungus with high efficiency and purity, showing it to be an economic and environmentally-friendly drug candidate (31). Our results revealed that terrein effectively inhibited the proliferation of both immortalized ovarian cancer cells and primary hOVCCs. Our investigation into the underlying mechanisms revealed that terrein induced $\mathrm{G}_{2} / \mathrm{M}$ phase cell cycle arrest by suppressing the expression of $\mathrm{G}_{2} / \mathrm{M}$ cell cycle-related proteins (cyclin $\mathrm{B} 1$ and Cdc2). More importantly, we identified that an important target of terrain is LIN28, an evolutionarily conserved protein which plays a critical role in embryonic development (38). LIN28 has also been reported to be an essential oncogene in ovarian cancer, contributing to the etiology and progression (41-43). Recently, LIN28 has gained increasing attention due to its biological roles in cancer stem cells, and is believed to be an important marker gene for cancer stem cells (43-45).

Consequently, we sought to investigate whether terrein has the ability to target CSLCs in our in vitro experimental system. We found that terrein effectively suppressed the expression of LIN28 and significantly reduced the viability of CSLCs, suggesting that terrein also possesses the ability to target cancer stem cells.

Thus, it can be concluded that terrein, an easily produced small molecule, may prove to be a promising drug candidate for use in the treatment of human epithelial ovarian cancer with a novel mechanism of action targeting both differentiated and stem-like ovarian cancer cells.

\section{Acknowledgements}

The present study was supported by grants from the Shanghai Jiaotong University (YG2011ms13), the Shanghai Municipal
Health and Family Planning Commission (20134Y128), the Shanghai Jiaotong University School of Medicine (13XJ10067), the National Natural Science Foundation of China (No. 81401216) and the Shanghai Committee of Science and Technology (14YF1408200).

\section{References}

1. Schwartz PE: Current diagnosis and treatment modalities for ovarian cancer. Cancer Treat Res 107: 99-118, 2002.

2. Cho KR and Shih IeM: Ovarian cancer. Annu Rev Pathol 4: 287-313, 2009.

3. Sudo T: Molecular-targeted therapies for ovarian cancer: prospects for the future. Int J Clin Oncol 17: 424-29, 2012.

4. Foster R, Buckanovich RJ and Rueda BR: Ovarian cancer stem cells: working towards the root of stemness. Cancer Lett 338: 147-157, 2013.

5. Jemal A, Bray F, Center MM, Ferlay J, Ward E and Forman D: Global cancer statistics. CA Cancer J Clin 61: 69-90, 2011.

6. Dean M, Fojo T and Bates S: Tumour stem cells and drug resistance. Nat Rev Cancer 5: 275-284, 2005.

7. Dalerba P, Cho RW and Clarke MF: Cancer stem cells: models and concepts. Annu Rev Med 58: 267-284, 2007.

8. Nguyen LV, Vanner R, Dirks P and Eaves CJ: Cancer stem cells: an evolving concept. Nat Rev Cancer 12: 133-143, 2012.

9. Chen J, Li Y, Yu TS, McKay RM, Burns DK, Kernie SG and Parada LF: A restricted cell population propagates glioblastoma growth after chemotherapy. Nature 488: 522-526, 2012.

10. Driessens G, Beck B, Caauwe A, Simons BD and Blanpain C: Defining the mode of tumour growth by clonal analysis. Nature 488: 527-530, 2012.

11. Bapat SA, Mali AM, Koppikar CB and Kurrey NK: Stem and progenitor-like cells contribute to the aggressive behavior of human epithelial ovarian cancer. Cancer Res 65: 3025-3029, 2005.

12. Szotek PP, Pieretti-Vanmarcke R, Masiakos PT, Dinulescu DM, Connolly D, Foster R, Dombkowski D, et al: Ovarian cancer side population defines cells with stem cell-like characteristics and Mullerian Inhibiting Substance responsiveness. Proc Natl Acad Sci USA 103: 11154-11159, 2006.

13. Zhang S, Balch C, Chan MW, Lai HC, Matei D, Schilder JM, Yan PS, et al: Identification and characterization of ovarian cancer-initiating cells from primary human tumors. Cancer Res 68: 4311-4320, 2008.

14. Kondo T, Setoguchi T and Taga T: Persistence of a small subpopulation of cancer stem-like cells in the C6 glioma cell line. Proc Natl Acad Sci USA 101: 781-786, 2004.

15. Patrawala L, Calhoun T, Schneider-Broussard R, Zhou J, Claypool K and Tang DG: Side population is enriched in tumorigenic, stem-like cancer cells, whereas $\mathrm{ABCG} 2^{+}$and ABCG2- cancer cells are similarly tumorigenic. Cancer Res 65: 6207-6219, 2005.

16. Calcagno AM, Fostel JM, To KK, Salcido CD, Martin SE, Chewning KJ, Wu CP, et al: Single-step doxorubicin-selected cancer cells overexpress the ABCG2 drug transporter through epigenetic changes. Br J Cancer 98: 1515-1524, 2008.

17. Schmandt RE, Broaddus R, Lu KH, Shvartsman H, Thornton A, Malpica A, Sun C, et al: Expression of c-ABL, c-KIT, and platelet-derived growth factor receptor- $\beta$ in ovarian serous carcinoma and normal ovarian surface epithelium. Cancer 98: 758-764, 2003.

18. Ma L, Lai D, Liu T, Cheng W and Guo L: Cancer stem-like cells can be isolated with drug selection in human ovarian cancer cell line SKOV3. Acta Biochim Biophys Sin 42: 593-602, 2010.

19. Lai D, Wang F, Chen Y, Wang C, Liu S, Lu B, Ge X, et al: Human ovarian cancer stem-like cells can be efficiently killed by $\gamma \delta \mathrm{T}$ lymphocytes. Cancer Immunol Immunother 61: 979-989, 2012.

20. Liu T, Cheng W, Lai D, Huang Y and Guo L: Characterization of primary ovarian cancer cells in different culture systems. Oncol Rep 23: 1277-1284, 2010.

21. Luo X, Dong Z, Chen Y, Yang L and Lai D: Enrichment of ovarian cancer stem-like cells is associated with epithelial to mesenchymal transition through an miRNA-activated AKT pathway. Cell Prolif 46: 436-446, 2013.

22. Raistrick H and Smith G: Studies in the biochemistry of microorganisms: the metabolic products of Aspergillus terreus Thom. A new mould metabolic product-terrein. Biochem J 29: 606-611, 1935. 
23. Ghisalberti EL, Narbey MJ and Rowland CY: Metabolites of Aspergillus terreus antagonistic towards the take-all fungus. J Nat Prod 53: 520-522, 1990.

24. Arakawa M, Someno T, Kawada M and Ikeda D: A new terrein glucoside, a novel inhibitor of angiogenin secretion in tumor angiogenesis. J Antibiot (Tokyo) 61: 442-448, 2008.

25. Park SH, Kim DS, Kim WG, Ryoo IJ, Lee DH, Huh CH, Youn SW, Yoo ID and Park KC: Terrein: a new melanogenesis inhibitor and its mechanism. Cell Mol Life Sci 61: 2878-2885, 2004.

26. Phattanawasin P, Pojchanakom K, Sotanaphun U, Piyapolrungroj $\mathrm{N}$ and Zungsontiporn S: Weed growth inhibitors from Aspergillus fischeri TISTR 3272. Nat Prod Res 21: 1286-1291, 2007.

27. Kim DS, Cho HJ, Lee HK, Lee WH, Park ES, Youn SW and Park KC: Terrein, a fungal metabolite, inhibits the epidermal proliferation of skin equivalents. J Dermatol Sci 46: 65-68, 2007.

28. Lee JC, Yu MK, Lee R, Lee YH, Jeon JG, Lee MH, Jhee EC, Yoo ID and Yi HK: Terrein reduces pulpal inflammation in human dental pulp cells. J Endod 34: 433-437, 2008.

29. Lee YH, Lee NH, Bhattarai G, Oh YT, Yu MK, Yoo ID, Jhee EC and Yi HK: Enhancement of osteoblast biocompatibility on titanium surface with Terrein treatment. Cell Biochem Funct 28: 678-685, 2010

30. Kim DS, Lee HK, Park SH, Lee S, Ryoo IJ, Kim WG, Yoo ID, et al: Terrein inhibits keratinocyte proliferation via ERK inactivation and $\mathrm{G}_{2} / \mathrm{M}$ cell cycle arrest. Exp Dermatol 17: 312-317, 2008.

31. Xu B, Yin Y, Zhang F, Li Z and Wang L: Operating conditions optimization for (+)-terrein production in a stirred bioreactor by Aspergillus terreus strain PF-26 from marine sponge Phakellia fusca. Bioprocess Biosyst Eng 35: 1651-1655, 2012.

32. Yin Y, Gao Q, Zhang F and Li Z: Medium optimization for the high yield production of single (+)-terrein by Aspergillus terreus strain PF26 derived from marine sponge Phakellia fusca. Process Biochem 47: 887-891, 2012.

33. Chen YF, Dong Z, Xia Y, Tang J, Peng L, Wang S and Lai D: Nucleoside analog inhibits microRNA-214 through targeting heat-shock factor 1 in human epithelial ovarian cancer. Cancer Sci 104: 1683-1689, 2013

34. Cicenas $\mathrm{J}$ and Valius M: The CDK inhibitors in cancer research and therapy. J Cancer Res Clin Oncol 137: 1409-1418, 2011.

35. Collins I and Garrett MD: Targeting the cell division cycle in cancer: CDK and cell cycle checkpoint kinase inhibitors. Curr Opin Pharmacol 5: 366-373, 2005
36. Hafner M, Max KE, Bandaru P, Morozov P, Gerstberger S, Brown M, Molina $\mathrm{H}$ and Tuschl T: Identification of mRNAs bound and regulated by human LIN28 proteins and molecular requirements for RNA recognition. RNA 19: 613-626, 2013.

37. Li N, Zhong X, Lin X, Guo J, Zou L, Tanyi JL, Shao Z, et al: Lin-28 homologue A (LIN28A) promotes cell cycle progression via regulation of cyclin-dependent kinase 2 (CDK2), cyclin D1 (CCND1), and cell division cycle 25 homolog A (CDC25A) expression in cancer. J Biol Chem 287: 17386-17397, 2012.

38. Moss EG, Lee RC and Ambros V: The cold shock domain protein LIN-28 controls developmental timing in C. elegans and is regulated by the lin-4 RNA. Cell 88: 637-646, 1997.

39. Shyh-Chang N and Daley GQ: Lin28: primal regulator of growth and metabolism in stem cells. Cell Stem Cell 12: 395-406, 2013.

40. Xu B, Zhang K and Huang Y: Lin28 modulates cell growth and associates with a subset of cell cycle regulator mRNAs in mouse embryonic stem cells. RNA 15: 357-361, 2009.

41. Viswanathan SR, Powers JT, Einhorn W, Hoshida Y, Ng TL, Toffanin S, O'Sullivan M, et al: Lin28 promotes transformation and is associated with advanced human malignancies. Nat Genet 41: 843-848, 2009.

42. Lu L, Katsaros D, Shaverdashvili K, Qian B, Wu Y, de la Longrais IA, Preti M, et al: Pluripotent factor lin-28 and its homologue lin-28b in epithelial ovarian cancer and their associations with disease outcomes and expression of let-7a and IGF-II. Eur J Cancer 45: 2212-2218, 2009.

43. Peng S, Maihle NJ and Huang Y: Pluripotency factors Lin28 and Oct4 identify a sub-population of stem cell-like cells in ovarian cancer. Oncogene 29: 2153-2159, 2010.

44. Yang X, Lin X, Zhong X, Kaur S, Li N, Liang S, Lassus H, et al: Double-negative feedback loop between reprogramming factor LIN2 8 and microRNA let-7 regulates aldehyde dehydrogenase 1-positive cancer stem cells. Cancer Res 70: 9463-9472, 2010.

45. Ma W, Ma J, Xu J, Qiao C, Branscum A, Cardenas A, Baron AT, et al: Lin28 regulates BMP4 and functions with Oct4 to affect ovarian tumor microenvironment. Cell Cycle 12: 88-97, 2013.

46. Sanchez-Garcia I, Vicente-Duenas C and Cobaleda C: The theoretical basis of cancer-stem-cell-based therapeutics of cancer: can it be put into practice? Bioessays 29: 1269-1280, 2007. 